\title{
Characteristics of Persistent or Recurrent Differentiated Thyroid Cancer
}

\author{
Annelie Kérékou Hodé1,2, Siham El Aziz², Alihonou Dédjan",2, Asma Chadli², Ahmed Farouqi² \\ ${ }^{1}$ Endocrinology, Metabolism and Nutrition Department, CNHU-HKM, Cotonou, Bénin \\ ${ }^{2}$ Endocrinology, Diabetology and Metabolic Diseases Department, Ibn Rochd University Hospital Center of Casablanca, \\ Casablanca, Morocco \\ Email: kerekouannelie@yahoo.fr
}

How to cite this paper: Hodé, A.K., El Aziz, S., Dédjan, A., Chadli, A. and Farouqi, A. (2020) Characteristics of Persistent or Recurrent Differentiated Thyroid Cancer. Open Journal of Endocrine and Metabolic Diseases, 10, 1-5.

https://doi.org/10.4236/ojemd.2020.101001

Received: October 30, 2019

Accepted: January 10, 2020

Published: January 13, 2020

Copyright (c) 2020 by author(s) and Scientific Research Publishing Inc. This work is licensed under the Creative Commons Attribution International License (CC BY 4.0).

http://creativecommons.org/licenses/by/4.0/

\section{Open Access}

\begin{abstract}
Introduction: The differentiated thyroid cancer has generally an excellent prognosis after the treatment. The aim of this study is to describe the characteristics of persistent or recurrent differentiated thyroid cancers. Patients/ Methods: It is about a descriptive and retrospective study conducted from 392 patients followed for differentiated thyroid cancer. The data concerning the persistent or recurrent differentiated thyroid cancer have been collected from 1986 to 2015 in endocrinology service in Ibn Rochd CHU. Results: In total, twenty-four patients have shown the relapse or the persistency of their tumor, corresponding to the prevalence of 6.12 percent. The papillary carcinoma was dominant in 79 percent of cases and the follicular carcinoma in 21 percent of cases. The metastases were cerebral (two cases), lung ( 3 cases), bones ( 3 cases, Figure 1), and lymph nodes (9 cases). In our series, eighteen cases of persistent differentiated thyroid cancer have been found against six cases of recurrent differentiated thyroid cancer. Two cases of death at least three years of followed in our series and concerned the two cases of cerebral metastasis. Conclusion: The persistent or recurrent differentiated thyroid cancer rate is low in our series. The discovery of the relapse $t$ is late.
\end{abstract}

\section{Keywords}

Differentiated, Thyroid, Cancer, Metastasis

\section{Introduction}

The differentiated thyroid cancer has generally an excellent prognosis after the treatment but the life expectancy of patients is reduced to sixty percent in persistent or recurrent differentiated thyroid cancer. Monitoring of recurrence/ persistence, although programmed in the follow-up of patients is often difficult 
in developing country. This was related to patients lost to follow-up and inaccessibility of diagnostic tools. The aim of this study realized in a single medical center was to describe the characteristics of persistent or recurrent differentiated thyroid Cancers and to compare our results to others.

Patients/methods: It is about a descriptive and retrospective study conducted from 392 patients followed for differentiated thyroid cancer. The data concerning the persistent or recurrent differentiated thyroid cancer have been collected from 1986 to 2015 in endocrinology service in Ibn Rochd CHU in Casablanca. The data collected were: treatment, histotype, TNM status, and follow up duration. The recurrent of differentiated thyroid cancer specifies itself as the appearance of the clinical and/or biological and/or radiological manifestations of differentiated thyroid cancers after a year of initial treatment. The persistency of differentiated thyroid cancer means a positive thyroglobulin and/or the expansion of the anti-thyroglobulin antibody and/or the radiologic highlighting of the tumor/swelling in the twelve months that followed the initial treatment. The analysis of the data has been made by the software SPSS 20.0.

\section{Results}

In total, twenty-four patients have shown the relapse or the persistency of their tumor, corresponding to the prevalence of 6.12 percent. The average age was $48 \pm 7$ years. The sex-ratio H/F was 0.3 . They have all had a total thyroidectomy. Fifty percent of them have lymph node dissection.

The papillary carcinoma was dominant in 79 percent of cases and the follicular carcinoma in 21 percent of cases (Table 1).

As far as the ablative iratherapy is concerned, 54 percent of them have it within an average period of 6.6 months

The average duration of the ascertaining of the relapse was 43.89 months after the initial surgery.

The metastases were cerebral (two cases), lung ( 3 cases), bones ( 3 cases) (Figure 1 ) and lymph nodes (9 cases).

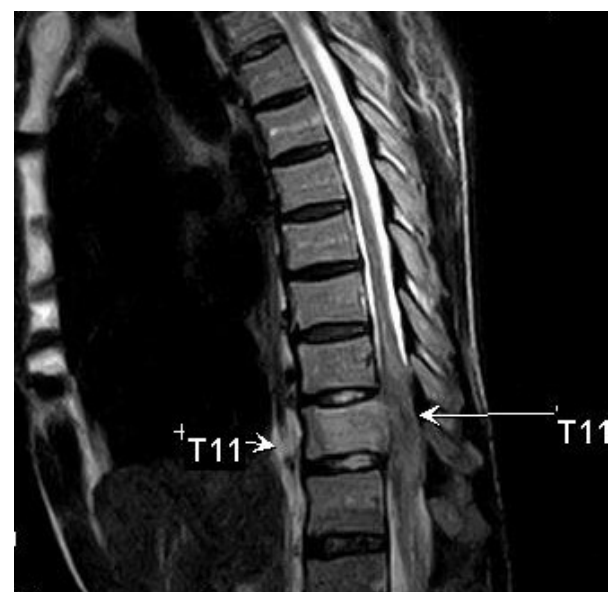

Figure 1. Papillary carcinoma metastasis in bone. 
Table 1. Demographic characteristic.

\begin{tabular}{ll}
\hline Characteristic & \\
\hline No. of patients & 24 \\
Follow up of from metastase's detection (month) & 43.89 \\
Sex ratio H/F & 0.3 \\
Age, median (years) & 48 \\
Histotypes (percent) & \\
-Papillary & $79 \%$ \\
-Follicular & $21 \%$ \\
TNM status (number) & \\
-T1a & \\
-T1b & 4 \\
-T2 & 7 \\
-T3 & 12 \\
-T4a & 1 \\
-No & 8 \\
-Nx & \\
-N1a & $50 \%$ \\
-N1b & $64 \%$ \\
Risks categories (number) & 3 \\
-ATA low risk & \\
-ATA intermediate risk & \\
-ATA high risk & \\
Chirurgy with curage & \\
Chirurgy without curage & \\
RAI use & \\
-Post surgical 131/use ablation & \\
-No use & \\
\hline & \\
\hline
\end{tabular}

In our series, eighteen cases of persistent differentiated thyroid cancer have been found against six cases of recurrent differentiated thyroid cancer.

The majority of tumour (66.6\%) was classified as intermediary risk according to American Thyroid Association risks categories.

Two cases of death at least three years of followed in our series and concerned the two cases of cerebral metastasis

\section{Discussion}

The average age of $48 \pm 7$ years of our population in our study is similar to 45.8 years found by Sapuppo G et al. [1]. As for the ratio sex, it is comparable to that found in several studies where the female predominency has been remarked [2]. The papillary carcinoma predominency in our study is without surprise as it is also majority in several studies [2] [3] [4]. The rate of persistent or recurrent differentiated thyroid cancer in our series is $6.12 \%$, low to the rates of the literature. Thus the patients treated for differentiated thyroid cancer showed a persistency or a relapse of the sickness in 20 percents of the case according to Haugen et al. [3]. This low rate is certainly related to the size of our sample. 
The iratherapy has been realized in more than the half of patients but still remains low in comparison to other studies [2]. Higashi $\mathrm{T}$ et al. showed that iratherapy 6 month surgery was associated to poor survival [5]. We didn't use the new treatment like ethanol ablation, radiofrequency ablation, kinase inhibitor therapy

The rate of persistent differentiated thyroid cancer cases are largely dominant in our study and are similar to results in several studies [1]. It has also been described that persistent differentiated thyroid cancer has more unfavorable outcomes than recurrences [1].

In our series, the patients classified into Stage 3 or 4 of TNM were more represented concordant with the results observed in the literature. The lymph nodes metastasis was more numerous than the extra thyroid metastasis which is found in the literature.

In our series, the prevalence of the cerebral metastasis is $8.3 \%$ which is upper to the data of the literature where the cerebral metastasis is rare in the differentiated thyroid cancer and their prevalence varies from 0.15 to 1.4 percent [6] [7] [8] [9] [10].

The prevalence of lung metastasis in our series (12.5\%) is inferior to that found by Hirsh D. et al. what was 85.6 percent [8]. As far as bone metastasis is concerned, they have a favorite seat, the vertebrate, pelvis, ribs [11].

The mortality is low in our series compared to other authors [1] [2]. These findings can be explained by the predominance of papillary cancers that have a more favorable prognosis than follicular [1]

Our study has several limits linked to retrospective nature and the number of patients.

\section{Conclusion}

The persistent or recurrent differentiated thyroid cancer rate is low in our series. The discovery of the recurrent is late. The cases of death have arisen in the patients, showing the cerebral metastasis corroborating the thesis according to what they followed decreases in case of metastasis to the distance of the differentiated thyroid cancer.

\section{Conflicts of Interest}

The authors declare no conflicts of interest regarding the publication of this paper.

\section{References}

[1] Sapuppo, G., Tavareli, M., Belfiore, A., et al. (2019) Time to Separate Persistent from Recurrent Differentiated Thyroid Cancer: Different Conditions with Different Outcomes. The Journal of Clinical Endocrinology \& Metabolism, 104, 258-265. https://doi.org/10.1210/jc.2018-01383

[2] Hirsch, D., Levy, S., Tsvetov, G., Gorshtein, A., Slutzky-Shraga, I., Akirov, A., et al. (2017) Long-Term Outcomes and Prognostic Factors in Patients with Differentiated 
Thyroid Cancer and Distant Metastases. Endocrine Practice, 23, 1193-1200. https://doi.org/10.4158/EP171924.OR

[3] Haugen, B.R., Alexander, E.K., Bible, K.C., et al. (2016) 2015 American Thyroid Association Management Guidelines for Adult Patients with Thyroid Nodules and Differentiated Thyroid Cancer: The American Thyroid Association Guidelines Task Force on Thyroid Nodules and Differentiated Thyroid Cancer. Thyroid, 26, 1-133. https://doi.org/10.1089/thy.2015.0020

[4] Géron, Y., Benbassat, C., Shteinshneider, M., et al. (2019) Long-Term Outcomes after Hemithyroidectomy for Papillary Thyroid Cancer: A Comparative Study and Review of the Literature. Cancers, 11, 26. https://doi.org/10.3390/cancers11010026

[5] Higashi, T., Nishii, R., Yamada, S., et al. (2011) Delayed Initial Radioactive Iodine Therapy Resulted in Poor Survival in Patients with Metastatic Differentiated Thyroid Carcinoma: A Retrospective Statistical Analysis of 198 Cases. Journal of Nuclear Medicine, 52, 683-689 https://doi.org/10.2967/jnumed.110.081059

[6] Kim, T.M., Kim, J.H., Yoo, R.E., Kim, S.C., Chung, E.J., Hong, E.K., et al. (2018) Persistent/RECURRENT Differentiated Thyroid Cancer: Clinical and Radiological Characteristics of Persistent Disease and Clinical Recurrence Based on Computed Tomography Analysis. Thyroid, 28, 1490-1499.

https://doi.org/10.1089/thy.2018.0151

[7] Gomes-Lima, C.J., Wu, D., Rao, S.N., et al. (2019) Brain Metastases from Differentiated Thyroid Carcinoma: Prevalence, Current Therapies and Outcomes. Journal of the Endocrine Society, 3, 359-371. https://doi.org/10.1210/js.2018-00241

[8] Parker, L.N., Wu, S.Y., Kim, D.D., et al. (1986) Recurrence of Papillary Thyroid Carcinoma Presenting as a Focal Neurologic Deficit. Archives of Internal Medicine, 146, 1985-1987.

[9] Chiu, A.C., Delpassand, E.S. and Sherman, S.I. (1997) Prognosis and Treatment of Brain Metastases in Thyroid Carcinoma. The Journal of Clinical Endocrinology \& Metabolism, 82, 3637-3642. https://doi.org/10.1210/jcem.82.11.4386

[10] Henriques de Figueiredo, B., Golbert, Y., Soubeyran, I., et al. (2014) Brain Metastases from Thyroid Carcinoma: A Retrospective Study of 21 Patients. Thyroid, 24, 270-276. https://doi.org/10.1089/thy.2013.0061

[11] Osorio, M., Sami, P., Moubayed, S.P., Su, H. and Urken, M.L. (2017) Systematic Review of Site Distribution of Bone Metastases in Differentiated Thyroid Cancer. Head Neck, 39, 812-818. https://doi.org/10.1002/hed.24655 